\title{
Morphologic study of the ascending aorta and aortic arch in hypoplastic left hearts: Surgical implications
}

André M. Ilbawi, BSE, ${ }^{a}$ Diane E. Spicer, BS, PA, ${ }^{\text {b }}$ Saroja Bharati, MD, ${ }^{c}$ Andrew Cook, PhD, ${ }^{d}$ and Robert $\mathrm{H}$. Anderson, MD

From the University of Pennsylvania, School of Medicine, Philadelphia, $\mathrm{Pa}^{\text {a }}$; the Congenital Heart Center, University of Florida College of Medicine. Gainesville, $\mathrm{Fla}^{\mathrm{b}}$; Advocate Hope Children's Hospital. Oak Lawn, Ill'; and the Cardiac Unit, Institute of Child Health, University College, London, United Kingdom. ${ }^{\mathrm{d}}$

Supported by a grant from University of Pennsylvania, School of Medicine, grants from the American Heart Association, Gerold L. Schiebler, MD, Chair in Pediatric Cardiology, University of Florida, and grants from the British Heart Foundation together with the Joseph Levy Foundation. The research on which this review is based was supported by grants from the Institute of Child Health and Great Ormond Street Hospital for Children NHS Trust benefits from $\mathrm{R} \& \mathrm{D}$ funding received from the NHS Executive.

Received for publication Oct 20, 2006; revisions received Jan 14, 2007; accepted for publication Jan 29, 2007.

Address for reprints: André Ilbawi, BSE, Box 399, Suite 100, Stemmler Hall, 3450 Hamilton Walk, Philadelphia, PA 191046087 (E-mail: ailbawi@mail.med.upenn. edu).

J Thorac Cardiovasc Surg 2007;134:99-105 $0022-5223 / \$ 32.00$

Copyright () 2007 by The American Association for Thoracic Surgery

doi:10.1016/j.jtcvs.2007.01.070
Objectives: The ascending aorta and aortic arch in patients with hypoplasia of the left heart are hypoplastic as a result of diminished blood flow. In this study, the presence and degree of obstruction owing to areas of narrowing or infolding within the diminutive aorta are quantified, and their surgical significance is discussed.

Methods: Ninety-six specimens with hypoplasia of the left heart were studied and measurements were taken at specified sites to evaluate areas of narrowing. Quantitative assessments of infoldings and their contribution to obstruction of flow are made.

Results: Narrowing of the distal ascending aorta was found in $60(62.5 \%)$ specimens, with a decrease in circumference of the distal ascending aorta $(0.72 \pm 1.06$ $\mathrm{mm})$ present when compared with its midpoint $(P<.05)$. Tissue infolding at the orifice of the brachiocephalic artery and its junction with the distal ascending aorta was observed in $56(58.3 \%)$ hearts, with major infolding in $29(30.2 \%)$ and minor infolding in $27(28.5 \%)$. Tissue infolding at this site correlated with a smaller ascending aorta $(P<.001)$ but not with narrowing in the distal ascending aorta $(P$ $=.53)$. Ductal coarctations were detected in $77(81.1 \%)$ specimens. Their presence correlated with a smaller diameter of the ascending aorta $(P<.05)$, and their severity correlated with the presence of aortic and mitral valvular atresia $(P<.05)$.

Conclusions: Important areas of obstruction in the ascending aorta in patients with hypoplasia of the left heart were found, and their pathogenesis is discussed. The findings highlight the importance of incorporating the ascending aorta into the aortic reconstruction at the time of initial palliation for patients with hypoplasia of the left heart.

$\mathrm{T}$ The Norwood procedure has become the standard method of palliation for patients born with hypoplastic left heart syndrome. An important step in this operation is the reconstruction of the aortic arch and ascending aorta to provide unobstructed systemic and coronary blood flow. ${ }^{1}$ Since its inception, the operation has undergone multiple modifications. Two strategies have been used in management of the ascending aorta. In one, the ascending aorta is incorporated into the neoaortic reconstruction either by a side-to-side or end-to-side aorta-pulmonary anastomosis. Although this technical modification eliminates all areas of obstruction in the ascending aorta, it may result in flattening and consequent obstruction of the anastomosis of the aortic orifice to the pulmonary trunk, especially when the aorta is small. ${ }^{2}$ In the other strategy, the ascending aorta is left untouched, either by anastomosing the pulmonary trunk to the aortic arch or by using the stented arterial duct as the systemic outflow. In hypoplastic left heart syndrome, coronary arterial perfusion depends exclusively on the retrograde flow through the long and hypoplastic ascending aorta. Any focal obstruction within the hypoplastic aorta will exacerbate coronary hypoperfusion and myocardial ischemia and may lead to death 
at or shortly after the initial stage of palliation. Thus, the frequency and extent of any focal areas of narrowing in the ascending aorta determine which of the two strategies should be the optimal surgical approach.

The pathogenesis of the obstructed areas in the ascending aorta, such as segments of narrowing or atypical infoldings of the arterial wall, may reflect hemodynamic abnormalities related to anomalous patterns of flow. The phasic alterations in flow as well as turbulence may cause lesions along the aortic wall and at the orifice of the arteries' branching from the ascending aorta and the aortic arch. ${ }^{3}$ Because there has been no complete study of these lesions, we have analyzed the frequency, the severity, and the nature of these narrowed areas of the ascending aorta in hypoplastic left heart syndrome. We have attempted to elucidate the pathogenesis of these narrowings and the contribution of abnormal patterns of flow and hemodynamics to their formation. By extension, we demonstrate the importance of the findings as they pertain to the selection of the optimal surgical approach.

\section{Materials and Methods: Criteria for Inclusion}

We identified 96 well-preserved specimens from the autopsy databases at Great Ormond Street Hospital for Children NHS Trust (London, United Kingdom), Hope Children's Hospital (Chicago, IIl), and the Van Mierop collection (Gainesville, Fla). The database was searched to identify the hearts obtained from patients with hypoplastic left heart syndrome, with the left ventricle being deemed too small at autopsy to sustain the systemic circulations, in the setting of normal segmental connections with mitral and/or aortic atresia or stenosis. Patients who had coexisting conditions or surgical intervention were excluded.

The postmortem specimens had all been fixed in formalin. The identified samples were evaluated to establish the salient morphologic characteristics. The specimens were classified according to the structure of the mitral and aortic valves, which included patent, stenotic, imperforate, or atretic. The systemic venous connections and coronary sinus were examined to identify any abnormalities. The atrial septum was classified as being intact, showing probe patency of the oval foramen, having a true deficiency within the floor of the oval fossa, or possessing fenestration of the flap valve. The general morphology of the tricuspid and pulmonary valves was investigated. Any abnormalities or defects of the ventricular septum or left atrial structure, if identified, excluded the specimen. The left ventricle was characterized as present or present only as a virtual slit in the inferior ventricular wall. When the ventricle was formed but hypoplastic, we measured the dimensions of the inflow and outflow tracts, grading endocardial fibroelastosis as major, minor, or absent.

We measured, and recorded in millimeters, the length of the ascending aorta; the aortic arch between the brachiocephalic and left common carotid arteries and between the left common carotid and left subclavian arteries; the isthmus; and the arterial duct. We measured circumferences within the arterial system by flattening and fully extending the arterial wall on a level plane, measuring in millimeters with a caliper and ruler. Such measurements were taken in the ascending aorta at the aortic sinuses (I); at the sinotubular junction (II); at the midpoint of the ascending aorta (III); proximal to the takeoff of the brachiocephalic artery (IV); distal to the brachiocephalic artery (V); distal to the left common carotid artery (VI); at the isthmus (VII); in the descending aorta distal to the ductal insertion (VIII); and near the level of the diaphragm. In similar fashion, we also measured the circumferences of the brachiocephalic artery, the right subclavian artery, the right and left common carotid arteries, the left subclavian artery, and the pulmonary trunk. Internal diameters of the vessels were calculated from the circumferences.

We studied the internal aspect of the ascending aorta, the aortic arch, and the descending aorta to identify narrowings or infoldings of the arterial walls. If found, narrowing in the ascending aorta was defined quantitatively as a decrease in the circumference of a vessel as it extended distally. Specifically, if the circumference of the ascending aorta just proximal to the brachiocephalic artery was smaller than the circumference of the midpoint of the ascending aorta, the specimen was labeled as narrowed. The entire ascending aorta was then measured to identify other focal abnormalities. Tissue infoldings were identified and classified as major, minor, or absent. The spectrum of severity was assigned as major when the ridge of tissue decreased the diameter by greater than $20 \%$ or minor when between $5 \%$ and $20 \%$, assessed by measuring adjacent internal circumferences and verified from diameters of the reconstructed vessel. This same criterion for major and minor lesions was also used for ductal coarctations. Special attention was paid to the orifices of the brachiocephalic, left common carotid, and left subclavian arteries. To corroborate the findings, we probed the arterial wall to distinguish the perceived abnormal findings from natural folds in a cut specimen. Coarctations in the environs of the duct were categorized as preductal or paraductal, depending on their position relative to the proximal ductal insertion. Photographs of representative samples were taken and saved digitally.

Statistical analysis of the data was conducted with Analyse-It, version 1.71, from Analyse-It Software, Ltd (Leeds, United Kingdom). To determine the variables associated with narrowing along the ascending aorta and tissue infolding, we used univariate analysis of variance for each variable, major, minor, or absent, assuming and validating equal variance. Categorical variables were compared by $\chi^{2}$ analysis. The presence of narrowing along the aorta was assessed by paired samples $t$ test. The funding agencies had no role in data interpretation.

\section{Results}

In total, 96 specimens were examined, 39 from Great Ormond Street Hospital (London, United Kingdom), 24 from Hope Children's Hospital (Chicago, Ill), and 33 from the Van Mierop collection (Gainesville, Fla) (Table 1). Of these specimens, $36(37.5 \%)$ had atretic or imperforate aortic and mitral valves, $48(50.0 \%)$ had an atretic or imperforate aortic valve with a patent or stenotic mitral valve, and 12 (12.5\%) had dysplastic aortic valvular stenosis with a patent or stenotic mitral valve. Left ventricular endocardial fibroelastosis was present in $53(89.5 \%)$ of the specimens with a patent mitral valve (Table 1).

The mean diameter at the midpoint of the ascending aorta was $2.3 \mathrm{~mm}$, with a range of 1.0 to $6.0 \mathrm{~mm}$. Narrowing 
TABLE 1. Summary of descriptive anatomic variables

\begin{tabular}{lc}
\hline & $\mathbf{n}$ (\% total) \\
\hline Mitral valve & \\
Patent & $40(41.7 \%)$ \\
Stenotic & $20(20.8 \%)$ \\
Imperforate & $4(4.2 \%)$ \\
Atretic & $32(33.3 \%)$ \\
Aortic valve & \\
Patent & $3(3.1 \%)$ \\
Stenotic & $9(9.4 \%)$ \\
Imperforate & $8(8.3 \%)$ \\
Atretic & $76(79.2 \%)$ \\
Left ventricle & \\
Cavity & \\
$\quad$ Present & $62(64.6 \%)$ \\
Absent & $34(35.4 \%)$ \\
Endocardial fibroelastosis & \\
Severe & $44(45.8 \%)$ \\
$\quad$ Mild & $7(7.3 \%)$ \\
Absent & $45(46.9 \%)$ \\
Atrial septum & \\
Intact & $6(6.3 \%)$ \\
Patent foramen ovale & $52(54.2 \%)$ \\
Oval fossa defect & $31(32.3 \%)$ \\
Fenestrated & $7(7.3 \%)$ \\
\hline
\end{tabular}

between the midpoint and distal ascending aorta was observed in $60(62.5 \%)$ specimens, whereas in $25(26.0 \%)$ there was no change in circumference. In the remaining 11 $(11.5 \%)$, the ascending aorta increased in size. For the entire group, the distal ascending aorta was smaller than the mid ascending aorta $(P<.001)$. The mean change in circumference was a decrease of $0.72 \mathrm{~mm}(95 \%$ confidence interval: $0.51-0.93 \mathrm{~mm}$ ). The greatest increase in circumference in the ascending aorta and aortic arch was found just distal to the orifice of the brachiocephalic artery when compared with the distal dimensions of the ascending aorta, with a mean increase of $2.7 \mathrm{~mm}$ (95\% confidence interval: $2.3-3.2$ $\mathrm{mm}$ ) (Figure 1).

We found a coarctation in the environs of the arterial duct in $77(81.1 \%)$ specimens, with approximately three fifths of these lesions being preductal (Table 2). One-way analysis of variance showed a correlation between the occurrence of coarctation and smaller size of the ascending aorta at its midpoint $(P<.001)$. The presence and severity of the lesions were related to the anatomic arrangements within the left ventricle: mitral $(P=.04)$ and aortic atresias $(P=.009)$ were associated with a larger proportion of ductal coarctations. The location of the coarctation lesion as preductal or paraductal was not dependent on any tested variable.

Infoldings involving the orifice of the brachiocephalic artery at its junction with the distal ascending aorta were present in 56 (58.3\%) specimens (Figure 2 and Table 2). A diminutive aorta increases the prevalence of tissue infolding: the smaller the ascending aorta, the greater the risk $(P<.001)$. This correlation was found for the circumference of the ascending aorta at the midpoint and distal end. A large expansion of circumference from the distal ascending aorta to the proximal aortic arch is also associated with an increased risk of infolding at the orifice of the brachiocephalic artery $(P<.001)$. The presence and extent of infolding, however, was independent of the presence or absence of narrowing along the distal end of the ascending aorta $(P=.53)$. Atresia as opposed to patency of the mitral valve also proved to correlate with lesions at the orifice of the brachiocephalic artery $(P<.001)$.

Infoldings and other vascular lesions were also found near the origins of the left common carotid and subclavian arteries. The orifice of the left common carotid artery possessed lesions of the vessel wall in $44(48.9 \%)$ evaluated specimens. No associated variable was identified. Infoldings at the orifice of the left subclavian artery were associated with the adjacent preductal or paraductal coarctation $(P=$ $.021)$; of the 30 specimens with abnormal morphologic characteristics at the orifice, $21(70.0 \%)$ lesions were secondary to an overriding ductal coarctation. The remaining lesions were found in specimens with an aberrant takeoff of the vessel or involvement of the adjacent left common carotid artery.

\section{Discussion}

The ascending aorta and aortic arch in patients with hypoplasia of the left heart are known to become hypoplastic as a result of the diminished flow during fetal life through the left ventricle and aortic outflow tract. ${ }^{4,5}$ To our knowledge, no morphologic analysis has yet demonstrated or quantified the presence of diffuse narrowing or sites of infolding within the diminutive aorta. Prior analyses of the ascending aorta have described a minute structure tapering down to the coronary arteries. ${ }^{6}$ In contrast, our measurements have identified the area of narrowing to be at the distal end of the ascending aorta, proximal to the orifice of the brachiocephalic artery. This area serves as the bottleneck of flow to the coronary arterial circulation and therefore has important surgical implications. Additionally, the correlation found between the presence of infoldings of the aortic wall and mitral atresia suggests that the infolding adjacent to the arterial orifices may be related to the abnormal patterns of flow of blood occurring during fetal life.

The hemodynamic molding theory suggests that the amount of growth of vessels and their morphologic characteristics are related to the flow of blood through them, shear stress, and stretching forces. ${ }^{7}$ In normal development, the systemic flow of blood from the left ventricle at systemic pressures acts as the stimulus for development of the as- 


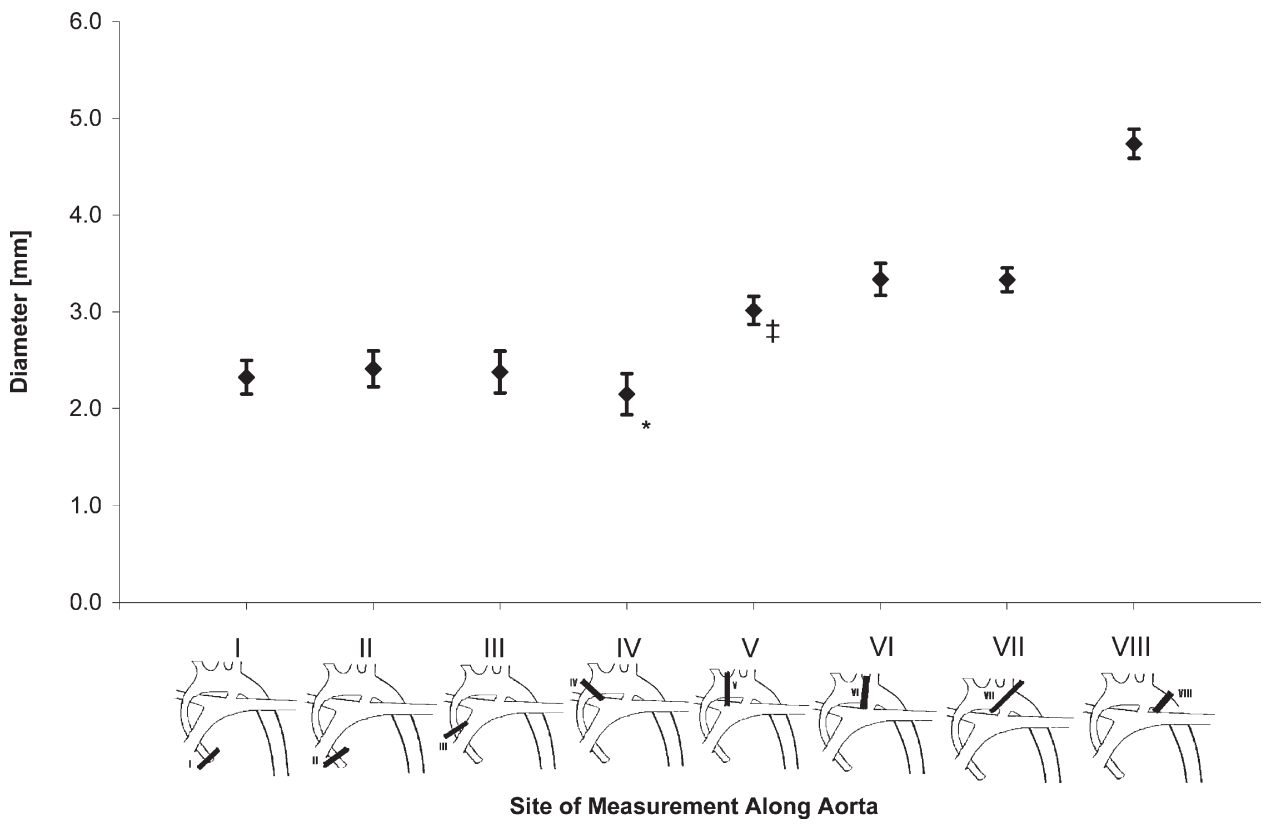

Figure 1. Diameters at 8 designated points along the ascending aorta and aortic arch. Please see text for exact measurement locations. The diameter at the distal end point of the ascending aorta (IV) is significantly smaller than the diameter at I, II, and III $\left.I^{*}\right)(P<.01)$, demonstrating narrowing. The diameter of the aortic arch distal to the orifice of the brachiocephalic (V) is significantly larger than the diameter at IV $(\mp)(P<.01)$. The error bars denote the $95 \%$ confidence intervals at each location.

cending aorta from the aortic sac. ${ }^{8}$ Conversely, the direction of flow in the ascending aorta in hypoplastic left heart syndrome is commonly described as retrograde, though this description has been disputed, even in cases with aortic atresia., ${ }^{3,9}$ When the ascending aorta receives only retrograde flow at low pressures, normal development of the aortic root and ascending aorta becomes impaired, and their diameters consequently hypoplastic. ${ }^{10}$ Accordingly, the ascending aorta has been described as the "common coronary artery," reflecting its limited development, reduced caliber, and minimized role to perfusion of the coronary arteries. ${ }^{3,8}$

Flow through the aorta must also be sufficient to maintain perfusion to the brain. As such, the orifice of the brachiocephalic artery acts less as a point of takeoff and more as a bifurcation with the "common coronary artery" along the retrograde route of systemic flow. The positive correlation between a diminutive aorta and infolding at the distal ascending aorta suggests these infoldings may function to augment the limited blood flow to the brain. The presence of infoldings also correlated with the extent of expansion of the arch just distal to the orifice of the brachiocephalic artery, implicating increased diversion of flow to that artery. Significant shear stresses arise at such bifurcations owing to turbulence, which can precipitate alterations in the morphologic characteriestics of the arterial wall. This hypothesis is consistent with both findings from this study and hypotheses regarding ductal coarctations, in which the abnormal morphology is thought to be a sequel of atypical flow. ${ }^{9}$ Weinberg and associates ${ }^{11}$ reported postmortem findings after first-stage palliation that included ridges at the orifice of the brachiocephalic artery, in the juxtaductal region, and near the proximal aortic anastomosis, areas associated with abnormal flow patterns.

Narrowing in the distal ascending aorta, on the other hand, may reflect impaired retrograde flow caused by competition with forward flow through the left ventricular outflow tract during fetal life before the onset of complete atresia. The resultant cyclic alterations of blood flow in the ascending aorta and aortic arch produce turbulence, tissue damage, and, ultimately, narrowing. ${ }^{3}$ The diminished flow in the ascending aorta and aortic arch decrease cellular and supportive connective tissue constituents of these vessels, causing formation of a densely packed layer of elastic lamellae. ${ }^{5}$ This process may contribute to both narrowing and tissue infolding.

Prenatal myocardial necrosis can be found in some patients with hypoplastic left heart syndrome. ${ }^{12}$ It seems possible that areas of narrowing or infolding as observed in our specimens may cause further postnatal myocardial damage. Intraoperative myocardial damage, increased strain on cardiac myocytes, and increased metabolic requirements predispose the tissue to subsequent ischemic changes. Postop- 
TABLE 2. Summary of descriptive vessel morphologic variables

\begin{tabular}{lc}
\hline & $\begin{array}{c}\mathbf{n}(\% \\
\text { total) }\end{array}$ \\
\hline $\begin{array}{l}\text { Ductal coarctation* } \\
\text { Total ductal coarctation }\end{array}$ & $77(81.1)$ \\
Preductal & \\
$\quad$ Major & $34(35.8)$ \\
Minor & $10(10.5)$ \\
Paraductal & \\
$\quad$ Major & $22(23.2)$ \\
$\quad$ Minor & $11(11.6)$ \\
No coarctation & $18(18.9)$ \\
Tissue infoldings & \\
Brachiocephalic artery orifice & \\
Total & \\
Major & $56(58.3)$ \\
Minor & $29(30.2)$ \\
$\quad$ No lesion & $27(28.1)$ \\
Left common carotid artery orifice & $40(41.7)$ \\
Total & \\
Major & $44(48.9)$ \\
Minor & $16(17.8)$ \\
No lesion & $28(31.1)$ \\
No coarctation at either orifice† & $46(51.1)$ \\
\hline
\end{tabular}

*The arterial duct was sufficiently intact for 95 of the 96 total specimens. tThe entire orifice of the left common carotid artery was adequately identifiable in 90 of the 96 total specimens.

erative consumption of oxygen is increased in the volumeand pressure-loaded right ventricle, and the diminutive left ventricle consumes substantial coronary arterial flow. ${ }^{13-15}$ Concomitantly, coronary arterial flow after first-stage palliation has less reserve. ${ }^{14}$ Low systemic blood flow resulting from myocardial dysfunction also impairs coronary flow. ${ }^{16}$ A further decrease in myocardial blood supply may be caused by a small ascending aorta (diameter less than 2 $\mathrm{mm}$ ), which has been reported as a risk factor for increased mortality in some series. ${ }^{17-19}$ Resultant insufficient coronary arterial perfusion has been accepted as a problem after the first stage of surgical repair, particularly because of the diastolic runoff associated with construction of a relatively large systemic-pulmonary arterial shunt. ${ }^{20}$ Impairment of coronary perfusion was found to be the leading cause of death after Norwood palliation in a study of 122 postmortem cases by Bartram, Grunenfelder, and Van Praagh, ${ }^{21}$ in which ischemic damage was found histologically in three quarters of specimens. Under these settings, coronary ischemia caused by a narrowed ascending aorta is an important etiologic factor of postoperative hemodynamic instability, decreased cardiac output, and secondary hypoxia. ${ }^{13}$ It is crucial during operative repair, therefore, that the aortic segments supplying the coronary arteries retain their max-

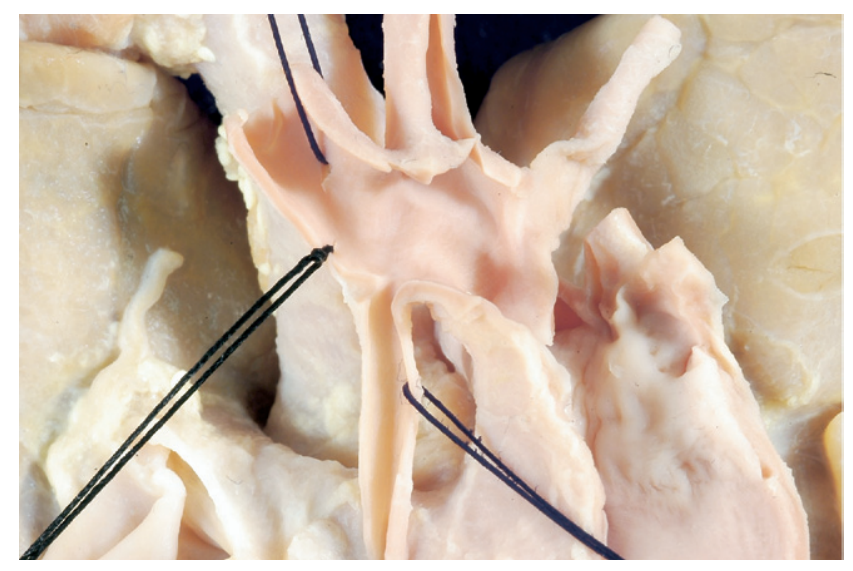

Figure 2. Major tissue infolding exists proximal to the orifice of the brachiocephalic artery. When the vessel is physically reconstructed, the narrowing along the entirety of the ascending aorta can also be appreciated.

imal patency and minimal resistance so as to ensure proper perfusion.

There are two main surgical strategies to the management of the ascending aorta in first-stage palliation. In one strategy, the ascending aorta is reconstructed either (1) with longitudinal incision and side-to-side anastomosis with the pulmonary trunk (Figure 3,A) or (2) by transection and end-to-side anastomosis to the neoaorta (pulmonary trunk) (Figure 3, B). Side-to-side anastomosis provides the highest patency with minimal obstruction and preserves the stimulus for growth and enlargement of the coronary arterial cross-sectional area- a factor important for long-term survival. ${ }^{15,19}$ The end-to-side anastomosis reduces the risk of obstruction associated with distal narrowing of the ascending aorta or the presence of infoldings at the junction of the distal ascending aorta with the brachiocephalic artery identified in this study. However, postoperative anastomotic narrowing and coronary arterial distortion may occur, particularly when the ascending aorta is less than $2.0 \mathrm{~mm}$ in diameter. ${ }^{21-24}$

In the other strategy, the ascending aorta is left unmodified. Surgical techniques that use this approach include (1) direct anastomosis of the proximal part of the pulmonary trunk to the underside of the aortic arch (Figure 3,C) and (2) use of a stented arterial duct as the systemic outflow and banding of the individual pulmonary arteries to limit pulmonary blood flow-the so-called hybrid approach (Figure $3, D$ ). The potential advantages of direct anastomosis include a shorter period of circulatory arrest, lower prevalence of compression of the left pulmonary artery, possible avoidance of a patch, and better long-term growth of the arch. ${ }^{22,23}$ The hybrid approach avoids the initial need for cardiopulmonary bypass and circulatory arrest in the newborn 


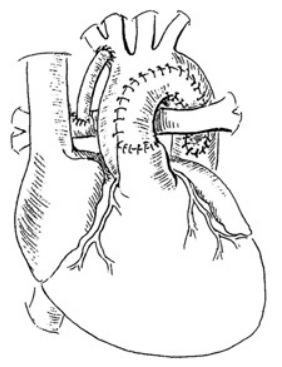

A

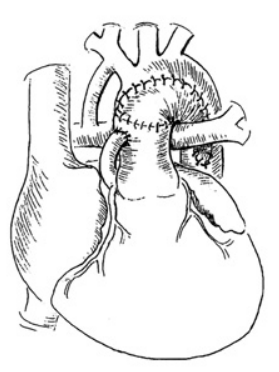

B

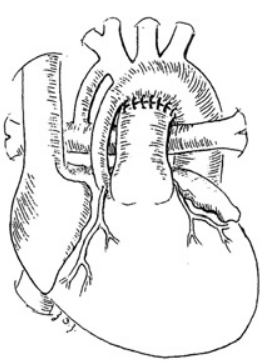

C

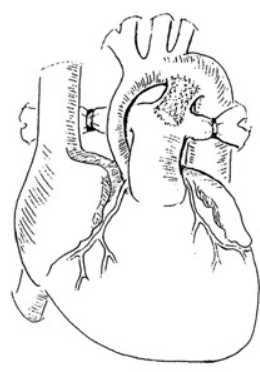

D

Figure 3. Surgical techniques used in first-stage palliation. One strategy involves reconstruction of the ascending aorta ( $A$ and $B$ ); the other strategy leaves it untouched (C and $D$ ).

period. ${ }^{25}$ The main drawback of not incorporating the ascending aorta or aortic arch, as in the hybrid technique, is leaving coronary perfusion dependent on retrograde flow through long, narrow, and potentially obstructed aortic segments. In a postmortem analysis, Poirier and colleagues ${ }^{23}$ reported transmural infarction of the right and left ventricles and ischemic myocardial changes when the pulmonary trunk was anastomosed to the underside of the aortic arch. Similarly, the study by Forbess and associates ${ }^{26}$ of 10 -year outcomes of patients undergoing first-stage palliation found that using this technique increased the risk of compromise to coronary arterial flow.

It is apparent, therefore, that the strategy of extending the incision to the proximal ascending aorta eliminates most areas of narrowing and increases the blood flow and pressure in the precoronary segment, ultimately allowing for its growth as a result of aortic adaptive changes. ${ }^{27}$ Mahle and his colleagues ${ }^{19}$ have confirmed that such tissue does grow after side-to-side anastomosis, further minimizing the risk of long-term obstruction. In contrast, leaving the ascending aorta unmodified does not adequately address the risk of precoronary stenosis and certainly does not remove the risk of obstruction occurring at the distal end point of the ascending aorta as a result of areas of narrowing or infolding, as found in our study.

Despite advancements in clinical and surgical care, patients born with hypoplastic left heart syndrome continue to have some of the highest mortality rates within the first year of life among all infants with congenital cardiac lesions. ${ }^{17} \mathrm{It}$ is axiomatic that increased understanding of the anatomy and hemodynamics will continue to enhance the outcomes of surgical intervention. We have examined in detail the morphology of the ascending aorta and aortic arch, placing particular attention on the junction of the ascending aorta with the orifice of the brachiocephalic artery. We have shown that abnormal architecture of the arterial walls in the aortic arch is associated with marked narrowing of the ascending aorta. The findings may be caused by the retro- grade patterns of flow and may underlie the deficient cardiac perfusion that is part of the hypoplastic left heart syndrome. If our data have functional significance, they suggest that the technique of incorporating the ascending aorta into the newly constructed aortic channel in first-stage palliation is to be favored over other approaches. It is important, however, to emphasize that technical alternatives that do not include the ascending aorta in the reconstruction may still have valid indications. Increased understanding of the hemodynamics, pathogenesis, and embryogenesis will continue to further elucidate the optimal surgical approach and improve the outcomes for neonates undergoing the Norwood sequence of operations.

We thank Vi Tram and Rachel Weinstein, $\mathrm{PhD}$, for their assistance in specimen preparation and statistical analysis review, respectively.

\section{References}

1. Norwood WI, Lang P, Casteneda AR, Campbell DN. Experience with operations for hypoplastic left heart syndrome. J Thorac Cardiovasc Surg. 1981;82511-9.

2. Kouchoukos NT, Blackstone EH, Doty DB, Hanley FL, Karp RB. In: Kirklin JW, Barratt-Boyes BG, editors. Cardiac surgery. 3rd ed. Philadelphia: Churchill Livingstone; 2003. p. 1387.

3. Lee ML, Wu MH, Wang JK, Chang CI, Lue HC. Flow characteristics in infants with hypoplastic left heart syndrome: an echocardiographic study. Zhonghua Min Guo Xiao Er Ke Yi Хие Hui Za Zhi. 1995;36: 14-9.

4. Hornberger LK, Need L, Benacerraf BR. Development of significant left and right ventricular hypoplasia in the second and third trimester fetus. J Ultrasound Med. 1996;15:655-9.

5. Becker AE. Segmental aortic hypoplasia or how to interpret the flow concept. Int J Cardiol. 1988;20:247-55.

6. Bharati S, Lev M. The surgical anatomy of hypoplasia of aortic tract complex. J Thorac Cardiovasc Surg. 1984;88:97-101.

7. Taber LA, Eggers DW. Theoretical study of stress-modulated growth in the aorta. J Theor Biol. 1996;40:143-52.

8. Bardo DM, Frankel DG, Applegate KE, Murphy DJ, Saneto RP Hypoplastic left heart syndrome. Radiographics. 2001;21:705-17.

9. Bharati S, Lev M. The pathology of congenital heart disease-a personal experience with more than 6300 congenitally malformed hearts. Armonk [NY]: Futura; 1996. p. 687-93. 
10. Simpson JM, Sharland GK. Natural history and outcome of aortic stenosis diagnosed prenatally. Heart. 1997;77:205-10.

11. Weinberg PM, Chin AJ, Murphy JD, Pigott JD, Norwood WI. Postmortem echocardiography and tomographic anatomy of hypoplastic left heart syndrome after palliative surgery. Am J Cardiol. 1986;58: 1228-32.

12. Lloyd TR, Evans TC, Marvin WJ Jr. Morphologic determinants of coronary blood flow in the hypoplastic left heart syndrome. Am Heart J. 1986;112:666-71.

13. Takabayashi S, Kado H, Shiokawa Y, Fukae K, Nakano T. Comparison of hemodynamics between Norwood procedure and systemic-topulmonary artery shunt for single right ventricle patients. Eur J Cardiothorac Surg. 2005;27:968-74.

14. Donnelly JP, Raffel DM, Shulkin BL, Corbett JR, Bove EL, Mosca RS, et al. Resting coronary flow and coronary flow reserve in human infants after repair or palliation of congenital heart defects as measured by positron emission tomography. J Thorac Cardiovasc Surg. 1998; 115:103-10.

15. Fogel MA, Rychik J, Vetter J, Donofrio MT, Jacobs M. Effect of volume unloading surgery on coronary flow dynamics in patients with aortic atresia. J Thorac Cardiovasc Surg. 1997;113:718-27.

16. Charpie JR, Dekeon MK, Goldberg CS, Mosca RS, Bove EL, Kulik TJ. Postoperative hemodynamics after Norwood palliation for hypoplastic left heart syndrome. Am J Cardiol. 2001;87:198-202.

17. Jenkins PC, Flanagan MF, Sargent JD, Canter CE, Chinnock RE, Jenkins $\mathrm{KJ}$, et al. A comparison of treatment strategies for hypoplastic left heart syndrome using decision analysis. J Am Coll Cardiol. 2001;38:1181-7.

18. Iannettoni MD, Bove EL, Mosca RS, Lupinetti FM, Dorostkar PC, Ludomirsky A, et al. Improving results with first-stage palliation for hypoplastic left heart syndrome. J Thorac Cardiovasc Surg. 1994;107: 934-40.
19. Mahle WT, Rychik J, Weinberg PM, Cohen MS. Growth characteristics of the aortic arch after the Norwood operation. J Am Coll Cardiol. 1998;32:1951-4.

20. Aiello VD, Ho SY, Anderson RH, Thiene G. Morphologic features of the hypoplastic left heart syndrome-a reappraisal. Pediatr Pathol. 1990;10(6):931-43.

21. Bartram U, Grunenfelder J, Van Praagh R. Causes of death after the modified Norwood procedure: a study of 122 postmortem cases. Ann Thorac Surg. 1997;64:1795-802.

22. Ishino K, Stumper O, De Giovanni JJ, Silove ED, Wright JG, Sethia B, et al. The modified Norwood procedure for hypoplastic left heart syndrome: early to intermediate results of 120 patients with particular reference to aortic arch repair. J Thorac Cardiovasc Surg. 1999;117: 920-30.

23. Poirier NC, Drummond-Webb JJ, Hisamochi K, Imamura M, Harrison AM, Mee RB. Modified Norwood procedure with a high-flow cardiopulmonary bypass strategy results in low mortality without late arch obstruction. J Thorac Cardiovasc Surg. 2000;120:875-84.

24. Nagy ZL, Parsons JM, Watterson KG. Repair of aortic atresia and hypoplastic left heart syndrome without using graft material. Eur J Cardiothorac Surg. 2000;17:85-7.

25. Bacha EA, Daves S, Hardin J, Abdulla RI, Anderson J, Kahana M, et al. Single-ventricle palliation for high-risk neonates: the emergence of an alternative hybrid stage I strategy. J Thorac Cardiovasc Surg. 2006;131:163-71.

26. Forbess JM, Cook N, Roth SJ, Serraf A, Mayer JE Jr, Jonas RA. Ten-year institutional experience with palliative surgery for hypoplastic left heart syndrome. Risk factors related to stage I mortality. Circulation. 1995; 92(9 Suppl):II262-6.

27. Machii M, Becker AE. Morphologic features of the normal aortic arch in neonates, infants, and children pertinent to growth. Ann Thorac Surg. 1997;64:511-5. 